\title{
Prepolysomnography evaluation can predict obstructive sleep apnea and is correlated to its severity
} Hend M. Esmaeel ${ }^{\mathrm{a}}$, Hamdy A. Mohammadien ${ }^{\mathrm{b}}$, Abd-Elbaset M. Saleh ${ }^{\mathrm{b}}$, Fatma H. Mohamed ${ }^{\mathrm{a}}$

\begin{abstract}
Background Obstructive sleep apnea (OSA) is increasingly identified as a disease with major health consequences. The limited availability of the gold standard diagnostic test, polysomnography (PSG), mandates careful clinical evaluation of suspected patients. This can allow better patient selection for referral for confirmatory diagnostic test.
\end{abstract}

Objective The study aimed at identifying the importance of pre-PSG evaluation in prediction of obstructive sleep apnea and its relation to disease severity.

Patients and methods A total of 170 patients were included. Detailed demographic characteristics, anthropometric measures, and comorbid conditions were recorded. Correlation to PSG results was done, and multivariate analysis was used to identify predictors of disease.

Results OSA was diagnosed in $58.8 \%$ of our studied patients. The patients with OSA and notably the severe subgroup were of older age, predominantly male, and current or ex-smoker. Mean BMI was highest in the patients with severe OSA (41.99 \pm 8.92 ) and same for mean neck and waist circumference, both were significantly higher in patients with severe OSA. In multivariate logistic regression analysis, significant predictive

\section{Introduction}

In the past two to three decades, obstructive sleep apnea (OSA) has been identified as an important cause of public health concern [1].

OSA remained underdiagnosed partly because of the costly nature and limited availability of the gold standard diagnostic test, polysomnography (PSG) $[2,3]$.

Careful clinical evaluation may identify patients at high risk of OSA who strongly need referral to diagnostic PSG.

\section{Study objective}

The aim was to analyze the role of demographic characteristics, anthropometric measures, and comorbid conditions as predictors of OSA and their relation to disease severity in our studied population sample.

\section{Patients and methods}

\section{Study design}

This was a cross-sectional study. It was conducted at sleep disordered breathing unit of the Chest Department. factors for OSA were older age, male sex, being nonemployed, having hypertension, and larger tonsillar size.

Conclusion Patient demographics, anthropometric characteristics, and presence of comorbid conditions such as hypertension are strong predictors of having OSA and justify referral for diagnostic sleep study.

Egypt J Bronchol 2019 13:556-562

() 2019 Egyptian Journal of Bronchology

Egyptian Journal of Bronchology 2019 13:556-562

Keywords: anthropometric measures, hypertension, obstructive sleep apnea

aDepartment of Chest Diseases, Sohag Faculty of Medicine, Sohag University, Sohag, 'Department of Chest Diseases, Faculty of Medicine, Mansoura University, Mansoura, Egypt

Correspondence to Hend M. Esmaeel, MD, Department of Chest Disease, Sohag University Hospital, Sohag 82524, Egypt. Tel: +20 112222 19134; fax: +20934702693;

e-mail: hendomr@gmail.com

Received: 25 February 2019 Revised: 8 April 2019

Accepted: 13 May 2019 Published: 25 October 2019

The study was approved by the faculty research ethics committee.

An informed written consent was obtained from all study patients.

\section{Study patients}

Adult patients aged more than 18 years attending the outpatient sleep clinic were consecutively recruited, with total inclusion of 170 patients.

\section{Methods}

All participants were subjected to the following:

(1) History taking.

(2) Thorough clinical examination.

(3) Anthropometric measurement:

(a) Weight $(\mathrm{kg})$ and standing height $(\mathrm{m})$ [4].

(b) BMI which is calculated by the following formula:

$$
\mathrm{BMI}=\operatorname{weight}(\mathrm{kg}) / \text { height }\left(\mathrm{m}^{2}\right)
$$

\footnotetext{
This is an open access journal, and articles are distributed under the terms of the Creative Commons Attribution-NonCommercial-ShareAlike 4.0 License, which allows others to remix, tweak, and build upon the work non-commercially, as long as appropriate credit is given and the new creations are licensed under the identical terms.
} 
Classification was made according to international WHO classification as follows [5].

Normal range: BMI 18.50-24.99.

Overweight: BMI more than or equal to 25.00.

Preobese: BMI 25.00-29.99.

Obese: BMI more than or equal to 30.00 .

Obese class I: BMI 30.00-34.99.

Obese class II: BMI 35.00-39.99.

Obese class III: BMI more than or equal to 40.00 .

(c) Neck circumference (NC):

$\mathrm{NC}$ was measured in the midway of the neck below the laryngeal prominence at the level of the cricothyroid membrane [6].

(d) Waist circumference (WC):

Follow the procedure according to the reference [7].

(4) Tonsillar size score [8]:

Tonsil size was graded from 0 to 4 . It consists of four classes representing the following criteria:

(a) Tonsil size 0: tonsils are absent (tonsillectomy or atrophied).

(b) Tonsil size 1: tonsils hidden within the pillars.

(c) Tonsil size 2: tonsil extending to the pillars.

(d) Tonsil size 3: tonsils are beyond the pillars but not to the midline.

(e) Tonsil size 4: implies tonsils that extend to the midline.

(5) Friedman tongue position (FTP) [9]:

It was used for palatal-tongue position with tongue in neutral position without tongue depressor or protrusion. The procedure is repeated five times so that the observer can assign the most accurate level. It consists of five classes: FTP-I, FTP-IIa, FTPIIb, FTP-III, and FTP-IV.

(6) Friedman obstructive sleep apnea hypoventilation syndrome (OSAHS) score [10]:

It was used as a screening system for OSAHS based on palate position (which is explained in FTP), tonsil size, and BMI. The BMI is graded as follows: grade $0=$ less than $20 \mathrm{~kg} / \mathrm{m}^{2}$, grade $1=20-25 \mathrm{~kg} / \mathrm{m}^{2}$, grade $2=25-30 \mathrm{~kg} / \mathrm{m}^{2}$, grade $3=30-40 \mathrm{~kg} / \mathrm{m}^{2}$, and grade $4=$ more than $40 \mathrm{~kg} /$ $\mathrm{m}^{2}$. Then we calculate the OSAHS score by the numerical values of these findings using the following formula:

$$
\begin{aligned}
\text { OSAHS } & =\mathrm{FTP}(0-\mathrm{IV})+\text { tonsil size } \\
& +\mathrm{BMI} \text { value }(0-4)
\end{aligned}
$$

Interpretation: any value more than 8 is considered as a positive OSAHS score, whereas any value less than 4 is considered a negative OSAHS score. Values in between are borderline and need more investigations.

(7) The additional investigations were as follows:

(a) Finger Pulse Oximeter.

(b) Arterial blood gases.

(c) Routine laboratory investigation.

(d) Pulmonary function test.

(e) ECG.

(f) Chest radiography.

(8) Full-night PSG:

All patients had attended full-night PSG using SOMNOscreen TMplus, version 2.2.0 (SOMNOmedics PSG, Somnomedocs GmbH., Randersacker, Germany). Data interpretation was done using the last available scoring manual [11]. Classification of patients into OSA and non-OSA and subclassification of OSA severity group was done using the international classification of sleep disorders [12].

\section{Statistical analysis}

STATA intercooled, version 14.2, was used for data analysis.

Multivariate regression analysis was used for identification of significant predictors for patients with OSA. Graphs were produced by STATA program (Stata Corp, California, USA). $P$ value was considered significant if it was less than 0.05 .

\section{Results}

The study participants $(n=170)$ after completing their clinical evaluation were classified according to PSG results as follows: with no OSA $(n=70)$, mild OSA $(n=21)$, moderate OSA $(n=11)$, and severe OSA $(n=68)$. Table 1 shows the sociodemographic characteristic of the studied population with pairwise comparison between non-OSA group and OSA groups of various severities. All factors show significant difference except for residence.

Comparison between non-OSA and OSA with various severity groups showed that mean $\mathrm{BMI}, \mathrm{NC}$, and $\mathrm{WC}$ were significantly higher in severe OSA in comparison with non-OSA and mild OSA groups. Almost $56 \%$ of patients with severe OSA were obese grade III (Table 2).

More than half of patients with OSA (54\%) had FTP grade III. Highest mean Friedman OSAS scoring value was measured in patients with severe OSA, and the difference in Friedman 
Table 1 Sociodemographic characteristic of studied population in relation to obstructive sleep apnea and its severity

\begin{tabular}{|c|c|c|c|c|c|c|}
\hline Variables & Non-OSA $(N=70)$ & Patients with OSA $(N=100)$ & Mild $(N=21)$ & Moderate $(N=11)$ & Severe $(N=68)$ & $P$ value \\
\hline \multicolumn{7}{|l|}{ Age (years) } \\
\hline Mean \pm SD & $41.74 \pm 15.00$ & $48.82 \pm 11.2$ & $40.24 \pm 11.83$ & $50.82 \pm 11.79$ & $51.06 \pm 9.99$ & \multirow[t]{2}{*}{$<0.0001^{\star}$} \\
\hline Median (range) & $39(25: 73)$ & $50(19: 79)$ & $40(19: 60)$ & $53(32: 70)$ & $52(31: 79)$ & \\
\hline \multicolumn{7}{|c|}{$P 1<0.0001^{*}, P 2=0.59, P 3=0.02^{*}, P 4=0.0001^{*}, P 5=0.04^{\star}, P 6=0.0009^{*}, P 7=1.00$} \\
\hline \multicolumn{7}{|c|}{$\operatorname{Sex}[n(\%)]$} \\
\hline Females & $65(92.86)$ & $47(47.00)$ & $11(52.38)$ & $6(54.55)$ & $30(44.12)$ & \multirow[t]{2}{*}{$<0.0001^{*}$} \\
\hline Males & $5(7.14)$ & $53(53.00)$ & $10(47.62)$ & $5(45.45)$ & $38(68.00)$ & \\
\hline \multicolumn{7}{|c|}{$P 1<0.0001, P 2<0.0001^{*}, P 3<0.0001^{*}, P 4<0.0001^{*}, P 5=0.91, P 6=0.51, P 7=0.52$} \\
\hline \multicolumn{7}{|c|}{ Occupation $[n(\%)]$} \\
\hline Employed & $32(45.71)$ & $27(27.00)$ & $3(14.29)$ & $2(18.18)$ & $22(32.35)$ & \multirow[t]{2}{*}{$<0.0001^{*}$} \\
\hline Not employed & $38(54.29)$ & $73(73)$ & $18(85.71)$ & $9(81.2)$ & $46(67.65)$ & \\
\hline \multicolumn{7}{|c|}{$P 1<0.0001, P 2<0.0001^{*}, P 3<0.0001^{*}, P 4<0.0001^{*}, P 5=0.62, P 6=0.006^{*}, P 7=0.40$} \\
\hline \multicolumn{7}{|c|}{ Smoking $[n(\%)]$} \\
\hline Current smoking & $5(7.14)$ & $22(22.0)$ & $2(9.52)$ & $2(18.18)$ & $18(26.47)$ & \multirow[t]{3}{*}{$<0.0001^{*}$} \\
\hline Nonsmoker & $65(92.86)$ & $66(66.00)$ & $17(80.95)$ & $9(81.82)$ & $40(58.82)$ & \\
\hline Ex-smoker & 0 & $12(12.00)$ & $2(9.52)$ & 0 & $10(14.71)$ & \\
\hline \multicolumn{7}{|c|}{$P 1<0.0001^{*}, P 2=0.03^{*}, P 3=0.23, P 4<0.0001^{*}, P 5=0.48, P 6=0.17, P 7=0.26$} \\
\hline \multicolumn{7}{|c|}{ Residence $[n(\%)]$} \\
\hline Rural & $43(61.43)$ & $70(70.00)$ & $12(57.14)$ & $6(54.55)$ & $52(76.47)$ & \multirow[t]{2}{*}{0.15} \\
\hline Urban & $27(38.57)$ & $30(30.00)$ & $9(42.86)$ & $5(45.45)$ & $16(23.53)$ & \\
\hline
\end{tabular}

OSA, obstructive sleep apnea. Analysis of variance and $\chi^{2}$ test. *Significant $P$ value. $P 1$ compared OSA with non-OSA, $P 2$ compared nonOSA and mild, $P 3$ non-OSA and moderate, $P 4$ non-OSA and severe, $P 5$ mild and moderate, $P 6$ mild and severe, $P 7$ moderate and severe.

Table 2 Comparison between severity of obstructive sleep apnea and anthropometric measures of studied populations

\begin{tabular}{|c|c|c|c|c|c|c|}
\hline Variables & Non-OSA $(N=70)$ & OSA $(N=100)$ & Mild $(N=21)$ & Moderate $(N=11)$ & Severe $(N=68)$ & $P$ value \\
\hline \multicolumn{7}{|l|}{ BMI } \\
\hline Mean \pm SD & $37.59 \pm 6.24$ & $40.02 \pm 9.42$ & $34.51 \pm 9.63$ & $38.31 \pm 8.19$ & $41.99 \pm 8.92$ & \multirow[t]{2}{*}{$0.0005^{\star}$} \\
\hline Median (range) & $35.9(29.3: 48.46)$ & $38.55(18.5: 66.95)$ & $34.3(18.5: 48.46)$ & $34.3(27.75: 55.5)$ & $40.9(26: 66.95)$ & \\
\hline \multicolumn{7}{|c|}{$P 1=0.06, P 2=0.74, P 3=1.00, P 4=0.008^{*}, P 5=1.00, P 6=0.001^{*}, P 7=0.94$} \\
\hline \multicolumn{7}{|c|}{$\mathrm{BMI}[n(\%)]$} \\
\hline Normal & 0 & $3(3.00)$ & $3(14.29)$ & 0 & 0 & \multirow[t]{5}{*}{$<0.0001^{*}$} \\
\hline Overweight & $10(14.29)$ & $9(9.00)$ & $5(23.81)$ & $1(9.09)$ & $3(4.41)$ & \\
\hline Obesity type I & $16(22.86)$ & $19(19.00)$ & $3(14.29)$ & $4(36.36)$ & $12(17.65)$ & \\
\hline Obesity type II & $21(30.00)$ & $23(23.00)$ & 7 (33.33) & $1(9.09)$ & $15(22.06)$ & \\
\hline Obesity type III & $23(32.86)$ & $46(46.00)$ & $3(14.29)$ & $5(45.45)$ & $38(55.88)$ & \\
\hline \multicolumn{7}{|c|}{$P 1=0.20, P 2=0.009^{*}, P 3=0.41, P 4=0.03^{*}, P 5=0.07, P 6<0.0001^{*}, P 7=0.39$} \\
\hline \multicolumn{7}{|c|}{ Neck circumference } \\
\hline Mean \pm SD & $40.74 \pm 2.88$ & $43.22 \pm 4.16$ & $41.14 \pm 3.71$ & $42.18 \pm 4.05$ & $44.02 \pm 4.10$ & \multirow[t]{2}{*}{$<0.0001^{*}$} \\
\hline Median (range) & $39(37: 46)$ & $43(33: 54)$ & $42(33: 50)$ & $44(35: 48)$ & $44(35: 54)$ & \\
\hline \multicolumn{7}{|c|}{$P 1<0.0001, P 2=1.00, P 3=1.00, P 4<0.0001^{*}, P 5=1.00, P 6=0.01^{*}, P 7=0.70$} \\
\hline \multicolumn{7}{|c|}{ Waist circumference } \\
\hline Mean \pm SD & $112.86 \pm 17.83$ & $118.26 \pm 19.19$ & $104.86 \pm 17.83$ & $114.45 \pm 16.20$ & $123.24 \pm 16.85$ & \multirow[t]{2}{*}{$0.0001^{*}$} \\
\hline Median (range) & $105(90: 140)$ & $120(70: 155)$ & $105(70: 142)$ & $120(95: 141)$ & $122(85: 155)$ & \\
\hline \multicolumn{7}{|c|}{$P 1=0.06, P 2=0.30, P 3=1.00, P 4=0.005^{\star}, P 5=0.72, P 6<0.0001^{*}, P 7=0.78$} \\
\hline
\end{tabular}

OSA, obstructive sleep apnea. Analysis of variance and $\chi^{2}$ test. ${ }^{*}$ Significant $P$ value. $P 1$ compared OSA with non-OSA, $P 2$ compared nonOSA and mild, $P 3$ non-OSA and moderate, $P 4$ non-OSA and severe, $P 5$ mild and moderate, $P 6$ mild and severe, $P 7$ moderate and severe.

OSAS score was significant between mild and severe case (Table 3).

Regarding comorbidities, diabetes mellitus, hypertension, and coronary artery disease were significantly more common in OSA than non-OSA patients (Fig. 1).
In this study, factors that showed significance in the univariate analysis were subjected to multivariate regression analysis with calculation of adjusted odds ratio with $95 \%$ confidence interval. Identification of independent variables for OSA prediction was done by final model. 
Table 3 Comparison between obstructive sleep apnea and Friedman tongue position, tonsillar size score, and Friedman obstructive sleep apnea syndrome scoring system of the studied populations

\begin{tabular}{|c|c|c|c|c|c|c|}
\hline Variables & Non-OSA $(N=70)$ & OSA $(N=100)$ & Mild $(N=21)$ & Moderate $(N=11)$ & Severe $(N=68)$ & $P$ value \\
\hline \multicolumn{7}{|l|}{ FTP $[n(\%)]$} \\
\hline FTP-I & 0 & $11(11.00)$ & $3(14.29)$ & 0 & $8(11.76)$ & \multirow[t]{5}{*}{0.09} \\
\hline FTP-Ila & $10(14.29)$ & $10(10.00)$ & $2(9.52)$ & $2(18.18)$ & $6(8.82)$ & \\
\hline FTP-Ilb & $25(35.71)$ & $22(22.00)$ & $6(28.57)$ & $2(18.18)$ & $14(20.59)$ & \\
\hline FTP-III & $34(48.57)$ & $54(54.00)$ & $9(42.86)$ & $6(54.55)$ & 39 (57.35) & \\
\hline FTP-IV & $1(1.43)$ & $3(3.00)$ & $1(4.76)$ & $1(9.09)$ & $1(1.47)$ & \\
\hline \multicolumn{7}{|c|}{$P 1=0.02^{*}, P 2=0.02^{*}, P 3=0.35, P 4=0.01^{*}, P 5=0.60, P 6=0.75, P 7=0.36$} \\
\hline \multicolumn{7}{|c|}{ Tonsillar size score $[n(\%)]$} \\
\hline Tonsil size 0 & $16(22.86)$ & $13(13.00)$ & $4(19.05)$ & $1(9.09)$ & $8(11.76)$ & \multirow[t]{5}{*}{$0.009^{*}$} \\
\hline Tonsil size 1 & $20(28.57)$ & $47(47.00)$ & $13(61.90)$ & $6(54.55)$ & $28(41.18)$ & \\
\hline Tonsil size 2 & $29(41.43)$ & $18(18.00)$ & $2(9.52)$ & $2(18.18)$ & $14(20.59)$ & \\
\hline Tonsil size 3 & $5(7.14)$ & $21(21.00)$ & $2(9.52)$ & $2(18.18)$ & $17(25.00)$ & \\
\hline Tonsil size 4 & 0 & $1(1.00)$ & 0 & 0 & $1(1.47)$ & \\
\hline \multicolumn{7}{|c|}{$P 1=0.001^{*}, P 2=0.02^{*}, P 3=0.14, P 4=0.002^{*}, P 5=0.71, P 6=0.25, P 7=0.94$} \\
\hline \multicolumn{7}{|c|}{ Friedman OSAS scoring system } \\
\hline Mean \pm SD & $7.17 \pm 1.67$ & $7.29 \pm 1.77$ & $6.14 \pm 1.59$ & $7.55 \pm 1.67$ & $7.61 \pm 1.73$ & \multirow[t]{2}{*}{$0.006^{*}$} \\
\hline Median (range) & $7(5: 11)$ & $7(3: 11)$ & $6(4: 10)$ & $8(4: 9)$ & $8(3: 11)$ & \\
\hline \multicolumn{7}{|c|}{$P 1=0.65, P 2=0.09, P 3=1.00, P 4=0.76, P 5=0.15, P 6=0.004^{*}, P 7=1.00$} \\
\hline \multicolumn{7}{|c|}{ Friedman OSAS scoring system $[n(\%)]$} \\
\hline Negative & 0 & $1(1.00)$ & 0 & 0 & $1(1.47)$ & \multirow[t]{3}{*}{0.37} \\
\hline Borderline & 52 (74.29) & $71(71.00)$ & $19(90.48)$ & 7 (63.64) & $45(66.18)$ & \\
\hline Positive & $18(25.71)$ & $28(28.00)$ & $2(9.52)$ & $4(36.36)$ & $22(32.35)$ & \\
\hline \multicolumn{7}{|c|}{$P 1=0.66, P 2=0.12, P 3=0.46, P 4=0.37, P 5=0.07, P 6=0.09, P 7=0.89$} \\
\hline
\end{tabular}

FTP, Friedman tongue position; OSA, obstructive sleep apnea. Student $t$ test and $\chi^{2}$ test. ${ }^{*}$ Significant $P$ value. $P 1$ compared OSA with non-OSA, $P 2$ compared non-OSA and mild, $P 3$ non-OSA and moderate, $P 4$ non-OSA and severe, $P 5$ mild and moderate, $P 6$ mild and severe, $P 7$ moderate and severe.

Figure 1

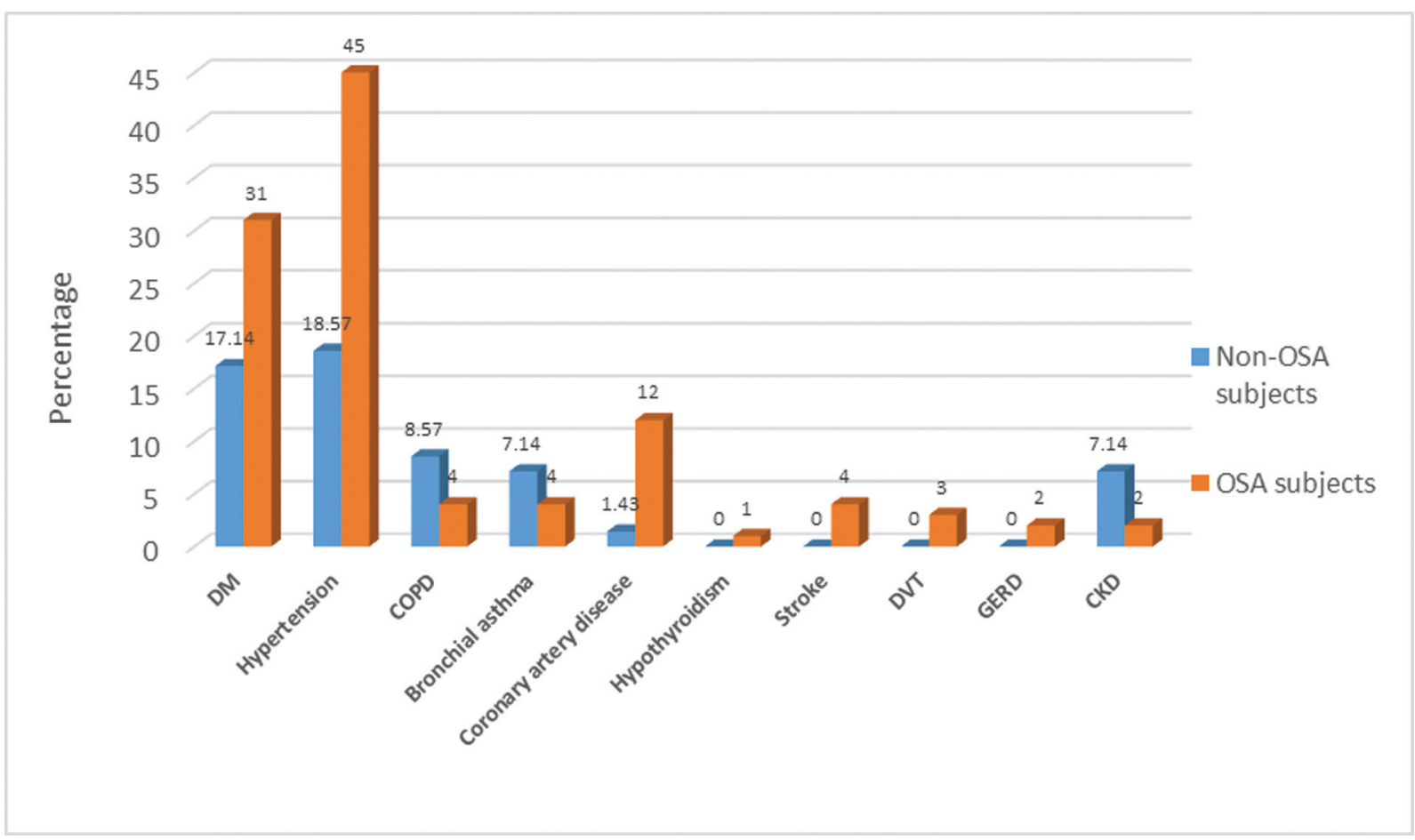

Comorbidities in the studied population.

Age, sex, hypertension, occupation, and tonsillar size score remained predictive of OSA in the final model (Tables 4 and 5).

\section{Discussion}

This study was conducted to detect the value of demographic, clinical, and comorbid characteristics 
Table 4 Multivariate analysis of predictive factors for obstructive sleep apnea

\begin{tabular}{|c|c|c|}
\hline Variables & Odds ratio $(95 \% \mathrm{Cl})$ & $P$ value \\
\hline Age (years) & $1.06(1.02: 1.10)$ & $0.006^{*}$ \\
\hline \multicolumn{3}{|l|}{ Sex } \\
\hline Females & 1 & $0.05^{\star}$ \\
\hline Males & $2.83(1.00: 8.01)$ & \\
\hline \multicolumn{3}{|l|}{ Occupation } \\
\hline Employed & 1 & $0.01^{*}$ \\
\hline Not employed & $18.56(1.90: 81.57)$ & \\
\hline \multicolumn{3}{|l|}{ Smoking } \\
\hline Nonsmoker or ex-smoker & 1 & $0.04^{*}$ \\
\hline Current smoking & 7.61 (1.09: 52.95) & \\
\hline Urban residence & $2.99(0.40: 40.02)$ & 0.17 \\
\hline $\mathrm{DM}$ & $1.81(0.50: 6.50)$ & 0.37 \\
\hline Hypertension & $6.12(1.57: 23.90)$ & $0.009^{*}$ \\
\hline Coronary artery disease & $1.56(0.14: 16.99)$ & 0.72 \\
\hline BMI & $1.02(0.92: 1.12)$ & 0.76 \\
\hline Neck circumference & $1.16(0.96: 1.39)$ & 0.13 \\
\hline Waist circumference & $0.98(0.94: 1.03)$ & 0.48 \\
\hline \multicolumn{3}{|l|}{ FTP } \\
\hline FTP-I/FTP-IIa & 1 & 0.06 \\
\hline FTP-IIb & $0.23(0.05-1.06)$ & 0.11 \\
\hline FTP-III & $0.29(0.06: 1.33)$ & 0.50 \\
\hline FTP-IV & $5.32(0.06: 291.68)$ & \\
\hline \multicolumn{3}{|l|}{ Tonsillar size score } \\
\hline Tonsil size 0 & 1 & 0.07 \\
\hline Tonsil size 1 & $3.73(0.90: 15.50)$ & 0.05 \\
\hline Tonsil size 2 & $0.14(0.03: 0.65)$ & 0.08 \\
\hline Tonsil size $3 / 4$ & $4.16(0.81: 21.27)$ & \\
\hline \multicolumn{3}{|c|}{ Friedman OSAS scoring system } \\
\hline Negative/borderline & 1 & 0.09 \\
\hline Positive & 0.07 (0.002: 1.54) & \\
\hline
\end{tabular}

$\mathrm{Cl}$, confidence interval; DM, diabetes mellitus; FTP, Friedman tongue position; OR, odds ratio; OSAS, obstructive sleep apnea syndrome. * Significant $P$ value.

Table 5 Final model of predictive factors for obstructive sleep apnea

\begin{tabular}{lcc}
\hline Variables & Odds ratio $(95 \% \mathrm{Cl})$ & $P$ value \\
\hline $\begin{array}{l}\text { Age (years) } \\
\text { Sex }\end{array}$ & $1.07(1.03: 1.11)$ & $0.001^{*}$ \\
$\quad$ Females & 1 & $0.02^{*}$ \\
$\quad$ Males & $3.23(1.25: 8.31)$ & \\
Occupation & & \\
$\quad$ Employed & 1 & $0.03^{*}$ \\
$\quad$ Not employed & $8.20(2.09: 32.17)$ & \\
Hypertension & $6.98(2.15: 22.64)$ & $0.006^{*}$ \\
Tonsillar size score & & \\
$\quad$ Tonsil size 0 & 1 & \\
$\quad$ Tonsil size 1 & $2.48(0.82: 7.51)$ & 0.11 \\
$\quad$ Tonsil size 2 & $0.12(0.03: 0.48)$ & $0.00^{*}$ \\
Tonsil size 3/4 & $4.17(1.04: 16.83)$ & $0.04^{*}$ \\
\hline
\end{tabular}

*Significant $P$ value.

in prediction of OSA and its severity, which was diagnosed by the PSG.

The study recruited 170 patients.
OSA was diagnosed in 100 (58.9\%) of our studied individuals. Other nationally published studies reported that $80 \%$ and 87.1 of their recruited patients were diagnosed as patients with OSA, respectively $[13,14]$.

The mean age of patients with OSA was significantly higher than non-OSA patients. Higher age showed 1.07-fold increased risk of having OSA. In agreement with our results, Martins et al. [15] proved that age is an independent risk factor for OSA with the assumption that this can be explained by the age-related reduction in muscle tone that results in decrease diameters of upper airway lumen. Researcher proved that the age effect was obesity independent [16].

Nearly two-thirds of the studied patients were female (65.88\%). Male sex was associated with a 3.23-fold higher risk of having OSA and increased risk of severity of the disease in the present study. Consistent reporting of higher OSA prevalence in men and association of OSA with male sex was found in the literature [17].

Explanation for this was made by different adipose tissue distribution, anatomical feature of upper airways, and different muscle function in men. Moreover, leptin and sex hormones exert their own endocrine effects in men [18].

Most of the patients in OSA in this study were not employed (73\%), with the risk of OSA being 8.20 higher than those who were employed. This may reflect the sequence of unhealthy sedentary life with subsequent weight gain. However, workers at stressful jobs were proved to be also at risk of OSA in a published research [19].

We found more current smokers in the OSA group (22\%) than in the non-OSA group (7.14) and the difference was statistically significant. However, smoking status did not show significance in the final model of regression analysis. Controversy was found in the literature about relation of smoking and OSA. Some researcher found it a nonsignificant risk factor for reporting sleep disordered breathing symptoms [20], whereas others reported that current and past smokers were significantly at higher risk of OSA [21].

Obesity is known as a major risk factor for OSA. The pathogenesis may be mediated by the primary effect of obesity in the form of fat deposition subcutaneously and intraluminal in the upper airway. This changed the upper airway compliance and predispose to its collapse [22]. The secondary effects of obesity on lung functions 
also mediate its pathogenic role in OSA [23]. This study used three measurement tools of body morphology: BMI, NC, and WC.

The study results showed that mean BMI was higher, and percentage of obese type II and III was higher in OSA than non-OSA participants. The difference in these parameters showed significance in relation to disease severity. This finding was in in accordance with many studies in the literature that documented the association between higher BMI and increased risk of OSA [24,25].

Our results revealed that higher tonsil size score according to Friedman classification was associated with nearly four-fold increased risk of having OSA in the final model of multivariate analysis. These findings are in accordance with the evidence in the literature that there is good correlation between the Friedman classification and the apnea-hypopnea index [10].

Regarding comorbidities, diabetes mellitus was found to be more prevalent in the OSA group than in nonOSA group and in particular in the severe OSA subgroup, and the difference was statistically significant. There is accumulating evidence in the literature about the association between OSA and diabetes mellitus. Some researchers reached to a conclusion in their review about this patient that sleep duration and quality are linked to the glycemic control in patients with type 2 diabetes [26].

In the final analysis model, hypertension was associated with 6.98-fold increased risk of having OSA. Hypertension and cardiovascular consequences are known to have important implications in the coexistence of obesity and OSA [27]. It is assumed that OSA is an essential differential diagnostic consideration in obese hypertensive patients [28].

In this study, factors identified by the final model of regression analysis as predictors for OSA were age, male sex, hypertension, and tonsillar size. These results are close to the published research work [29], as the researchers in this work concluded that sex, age, hypertension, and obesity are independent risk factors for OSA in their studied Saudi population, which is similar to results from western studies.

\section{Study strength}

OSA was confirmed in our study group by PSG, which adds reliability to our study results. Many published studies assessed the risk factors of OSA while utilizing validated simple questionnaires only without performing PSG [20,30].

\section{Study limitation}

One of the study limitations was that radiographic measure to directly quantify fat deposition in the upper airway was not done. However, this can be argued that we aimed at utilizing clinical evaluation and noncostly investigation to define their predictive ability. Other limitation was that it is a single-center study.

\section{Conclusion}

Detailed clinical evaluation, anthropometric measures, and presence of comorbidity could identify predictive factors for OSA and help in patient selection for referral for PSG diagnostic sleep study, which is relatively expensive and not widely available.

\section{Financial support and sponsorship \\ Nil.}

\section{Conflicts of interest}

There are no conflicts of interest.

\section{References}

1 Lam JC, Sharma SK, Lam B. Obstructive sleep apnoea: definitions, epidemiology \& natural history. Indian J Med Res 2010; 131:165-170.

2 Ulualp SO. Snoring and obstructive sleep apnea. Med Clin North Am 2010; 94:1047-1055.

3 Abrishami A, Khajehdehi A, Chung F. A systematic review of screening questionnaires for obstructive sleep apnea. Can J Anaesth 2010; 57:423-438

4 World Health Organization. Physical status: the use and interpretation of anthropometry. Technical Report Series No. 854. World Health Organization, Geneva, 1995. Available at: www.who.int/en/. [Accessed 20 March 2015].

5 WHO Expert Consultation. Appropriate body mass index for Asian populations and its implications for policy intervention strategies. Lancet 2004; 363:157-163.

6 Davies R, Ali N, Stradling J. Neck circumference and other clinical features in the diagnosis of the obstructive sleep apnoea syndrome. Thorax 1992; 47:101-105

7 Ostchega Y, Dillon C, Prineas RJ, McDowell M, Carroll M. Tables for the selection of correct blood pressure cuff size based on self-reported height and weight and estimating equations for mid-arm circumference: data from the U.S. National Health and Nutrition Examination Survey. J Hum Hypertens 2006; 20:15-22.

8 Friedman M, Ibrahim H, Bass L. Clinical staging for sleep-disordered breathing. Otolaryngol Head Neck Surg 2002; 127:13-21.

9 Friedman M, Tanyeri H, La Rosa M, Landsberg R, Vaidyanathan K, Pieri S, Caldarelli D. Clinical predictors of obstructive sleep apnea. Laryngoscope 1999; 109:1901-1907.

10 Friedman M, Soans R, Gurpinar B, Lin HC, Joseph NJ. Inter examiner agreement of Friedman tongue positions for staging of obstructive sleep apnea/hypopnea syndrome. Otolaryngol Head Neck Surg 2008; 139:372-377.

11 Berry RB, Brooks R, Gamaldo CE, Harding SM, Loyd RM, Marcus CL, Bradley VV. The AASM manual for the scoring of sleep and associated events: rules, terminology and technical specifications, version 2.3. Darien, IL: American Academy of Sleep Medicine; 2016.

12 American Academy of Sleep Medicine. Sateia M, ed. International classification of sleep disorders. Chapter 2 3rd ed. Darien, IL: American Academy of Sleep Medicine; 2014; 114-122. 
13 Suliman LA, Shalabi NM, Elmorsy AS, Moawed MK. Value of STOP-BANG and Berlin questionnaires in the diagnosis and severity prediction of obstructive sleep apnea hypopnea syndrome. Egypt J Bronchol 2017; 11:367-371.

$14 \mathrm{El}$-Sayed $\mathrm{IH}$. Comparison of four sleep questionnaires for screening obstructive sleep apnea. Egypt J Chest Dis Tuber 2012; 61:433-441.

15 Martins AB, Tufik S, Moura SM. Physiopathology of obstructive sleep apnea-hypopnea syndrome. J Bras Pneumol 2007; 33:93-100.

16 Young T, Shahar E, Nieto FJ, Redline S, Newman AB, Gottlieb DJ, et al. Sleep Heart Health Study Research Group.Predictors of sleep-disordered breathing in community-dwelling adults: the Sleep Heart Health Study. Arch Intern Med 2002; 162:893-900.

17 Mak KK, Ho SY, Thomas GN, Lo WS, Cheuk DK, Lai YK, et al. Smoking and sleep disorders in Chinese adolescents. Sleep Med 2010; 11:268-273.

18 Kapsimalis F, Kryger MH. Gender and obstructive sleep apnea syndrome: part 2.Mechanisms. Sleep 2002; 25:499-506.

19 Adewole OO, Hakeem A, Fola A, Anteyi E, Ajuwon Z, Erhabor G. Obsructive sleep apnea among adults in Nigeria. J Natl Med Assoc 2009; 101:720-725.

20 Hussain SF, Cloonan YK, Islam M, Rahbar MH. Prevalence and associated risk factors of sleep-disordered breathing symptoms in young and middle-aged Pakistani employed adults. Sleep Breath 2010; 14:137-144.

21 Olusola AS, Adegboyega O. Risk factors of obstructive sleep apnea among nigerian outpatients. Braz J Otorhinolaryngol 2012; 78:27-33.
22 Caples SM, Gami AS, Somers VK. Obstructive sleep apnea. Ann Intern Med 2005; 142:187-197.

23 Salome CM, King GG, Berend N. Physiology of obesity and effects on lung function. J Appl Physiol 2010; 108:206-211.

24 Reddy EV, Kadhiravan T, Mishra HK, Sreenivas V, Handa KK, Sinha S, et al. Prevalence and risk factors of obstructive sleep apnea among middle-aged urban Indians: a community-based study. Sleep Med 2009; 10:913-918.

25 Hiestand DM, Britz P, Goldman M, Phillips B. Prevalence of symptoms and risk of sleep apnea in the US population: results from the national sleep foundation sleep in America 2005 poll. Chest 2006; 130:780-786.

26 Shaun WHL, aKhuen YN, bWeng KC. The impact of sleep amount and sleep quality on glycemic control in type 2 diabetes: a systematic review and meta-analysis. Sleep Med Rev 2017; 31:91-101.

27 Wolk R, Shamsuzzaman AS, Somers VK. Obesity, sleep apnea, and hypertension. Hypertension 2003; 42:1067-1074.

28 Wolf J, Lewicka J, Narkiewicz K. Obstructive sleep apnea: an update on mechanisms and cardiovascular consequences. Nutr Metab Cardiovasc Dis 2007; 17:233-240.

29 Wali SO, Abalkhail B, Krayem A. Prevalence and risk factors of obstructive sleep apnea syndrome in a Saudi Arabian population. Ann Thorac Med 2017; 12:88-94.

30 Bahammam AS, Al-Rajeh MS, Al-Ibrahim FS, Arafah MA, Sharif MM. Prevalence of symptoms and risk of sleep apnea in middle-aged Saudi women in primary care. Saudi Med J 2009; 30:1572-1576. 